\title{
Review of Azoospermia
}

\author{
Matthew Wosnitzer ${ }^{1, *}$, Marc Goldstein ${ }^{2}$, and Matthew P Hardy ${ }^{1,3,4}$
}

\begin{abstract}
${ }^{1}$ Department of Urology and Institute for Reproductive Medicine; Weill Cornell Medical College of Cornell University; New York, NY USA; ${ }^{2}$.A.C.S; ${ }^{3}$ Director of the Center for Male Reproductive Medicine and Microsurgery; Weill Cornell Medical College of Cornell University; New York, NY USA; ${ }^{4}$ Center for Biomedical Research; The Population Council; New York, NY, USA
\end{abstract}

Keywords: male infertility, azoospermia, vasectomy reversal, vasovasostomy, vasoepididymostomy, microdissection testicular sperm extraction, non-obstructive azoospermia, obstructive azoospermia, microsurgical epididymal sperm aspiration

Azoospermia is classified as obstructive azoospermia (OA) or non-obstructive azoospermia (NOA), each having very different etiologies and treatments. The etiology, diagnosis, and management of azoospermia were reviewed and relevant literature summarized. Differentiation between these two etiologies is of paramount importance and is contingent upon thorough history and physical examination and indicated laboratory/genetic testing. OA occurs secondary to obstruction of the male reproductive tract, and is diagnosed through a combination of history/physical examination, laboratory testing, genetics (CFTR for congenital OA), and imaging studies. NOA (which includes primary testicular failure and secondary testicular failure) is differentiated from OA by clinical assessment (testis consistency/volume), laboratory testing (FSH), and genetic testing (karyotype, $\mathrm{Y}$ chromosome microdeletion, or specific genetic testing for hypogonadotropic hypogonadism). For obstructive azoospermia, management includes microsurgical reconstruction when feasible using microsurgical vasovasostomy or vasoepididymostomy. Microsurgical epididymal sperm aspiration with in vitro fertilization/intracytoplasmic sperm injection (IVF/ICSI) is utilized for those cases not amenable to reconstruction. NOA management includes medical management for congenital hypogonadotropic hypogonadism and microdissection testicular sperm extraction with IVF/ ICSI for appropriate candidates based on laboratory/genetic testing. Overall, this important review provides an updated summary of the most recent available literature describing etiology, diagnosis, and management of azoospermia.

\section{Introduction}

The absence of spermatozoa in the ejaculate (azoospermia) is identified in $15 \%$ of infertile men and can be classified as obstructive azoospermia (OA) and non-obstructive azoospermia (NOA). Thorough history-taking and physical examination are critical in the classification of azoospermia etiology and may be accompanied by laboratory and genetic testing. OA and NOA are managed by specific medical and/or surgical options. Recent advances in genetic testing and microsurgical approaches

*Correspondence to: Matthew Wosnitzer; Email: maw7011@med.cornell.edu Submitted: 01/12/2014; Revised: 02/13/2014; Accepted: 02/13/2014; Published Online: 03/31/2014

http://dx.doi.org/10.4161/spmg.28218 combined with assisted reproductive technology (ART) are providing options for increasing numbers of patients.

OA, which comprises $40 \%$ of azoospermia cases, is typically accompanied by preservation of normal exocrine and endocrine function, and normal spermatogenesis in the testis. ${ }^{1} \mathrm{OA}$ is the consequence of physical blockage to the male excurrent ductal system and may occur in any region between the rete testis and the ejaculatory ducts. ${ }^{2} \mathrm{NOA}$, the etiology affecting approximately $60 \%$ of azoospermic men, includes non-obstructive causes of azoospermia, including toxic exposures or abnormal testicular development. ${ }^{3} \mathrm{NOA}$ results from either primary testicular failure (elevated LH, FSH, small testes affecting up to $10 \%$ of men presenting with infertility), secondary testicular failure (congenital hypgonadotropic hypogonadism with decreased LH and FSH, small testes), or incomplete or ambiguous testicular failure (either increased FSH and normal volume testes, normal FSH and small testes, or normal FSH and normal testis volume).

\section{Etiology of OA}

Acquired causes of vasal obstruction include vasectomy, iatrogenic injury following inguinal hernia repair, or less commonly vasography performed with improper technique. Obstruction of the epididymis can occur as a result of increased epididymal intratubular pressure from extended vasal obstruction (in more than $50 \%$ of men with obstructive interval exceeding $15 \mathrm{y}$ after vasectomy, resulting in microscopic epididymal tubule rupture with sperm leakage causing epididymal sperm granuloma and epididymal obstruction), and following pelvic or scrotal trauma. Iatrogenic epididymal obstruction post-hydrocelectomy, percutaneous epididymal sperm aspiration (PESA), microsurgical epididymal sperm aspiration (MESA), or inadvertent epididymal biopsy may result due to technique. ${ }^{4}$ Congenital $\mathrm{OA}$ can be a result of congenital unilateral absence of the vas deferens (CUAVD) or congenital bilateral absence of the vas deferens (CBAVD) usually associated with mutations of the cystic fibrosis transmembrane regulator (CFTR) protein, which lead to absent vasa as well as partial or complete absence of the epididymis. Finally, severe inflammation of the epididymis (epididymitis), prostate, seminal vesicles, or lower genitourinary tract infection may lead to male excurrent ductal obstruction. Ejaculatory duct obstruction (EDO) can result from trauma, surgery, infection, or congenital 


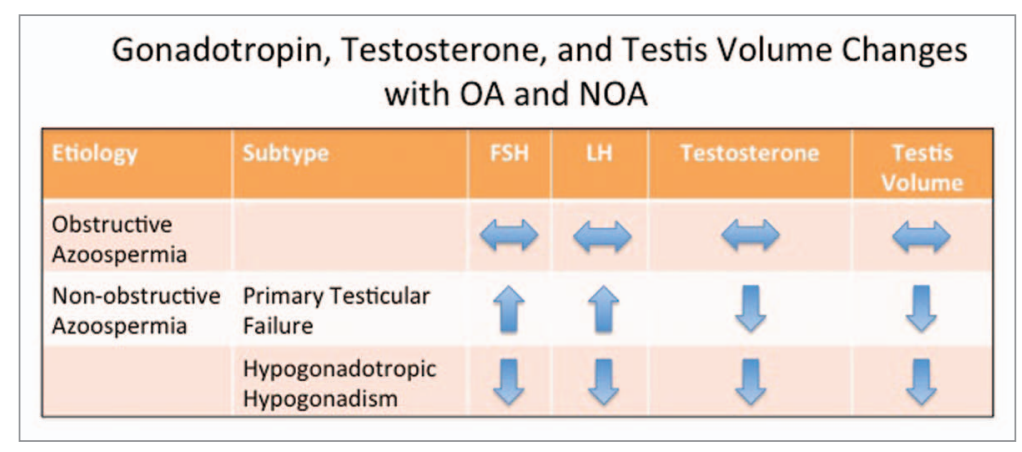

Figure 1. Changes in gonadotropins, testosterone, and testis volume associated with obstructive and non-obstructive azoospermia. vesicles, and prostatic cysts, which can help to confirm etiology of azoospermia. ${ }^{10}$ Associated disease with OA (CF symptoms) and NOA (increased risk of cardiovascular disease ${ }^{11}$ as well as testis cancer and colorectal cancer) should be considered based on physical exam, lab, and genetic abnormalities. ${ }^{12,13}$ For men with unclear etiology of azoospermia, testis biopsy may be indicated in select men with normal volume testes, normal vasa, negative anti-sperm antibody testing, and normal FSH levels.

\section{Management of OA}

Optimal management of vasal or epididymal Müllerian duct cysts and is characterized by low semen volume with a crystal clear watery appearance (due to absence of seminal vesicle component), low semen $\mathrm{pH}$, and absent fructose.

\section{Diagnosis of OA}

Differentiation between $\mathrm{OA}$ and NOA is usually possible with a good history and physical examination, including testicular volume assessment with OA demonstrating normal testicular volume and indurated epididymides, while NOA with small, soft testes and flat, soft epididymides. Aforementioned surgery, infection, or congenital abnormalities characterize OA along with history of successful prior fertility. Physical examination should focus on vasal gaps, location of vasectomy site (convoluted vas may carry increased risk of epididymal injury since pressure is dissipated over a shorter testicular vasal remnant), presence of granuloma at vasectomy site (a predictor of better microsurgical vasectomy reversal results ${ }^{5}$ ), and epididymal abnormalities including full or absent portions. Laboratory values, most significantly $\mathrm{FSH}$, is normal in $\mathrm{OA}$ and usually elevated in NOA due to lack of normal negative feedback on the hypothalamus and pituitary by inhibin B and testosterone (Fig. 1). Elevated FSH in OA may indicate an increased need for assisted reproductive technology post-vasectomy reversal. ${ }^{6}$ If unilateral obstruction exists, the contralateral non-obstructed side may allow fertility. If partial obstruction is present, severe oligospermia or oligoasthenoteratospermia may result. If the vas is absent unilaterally or bilaterally, CFTR mutation testing with recommended screening panels or DNA sequencing of the full CFTR gene is indicated. ${ }^{7,8}$ In men with unilateral CAVD and negative CFTR mutation testing, renal ultrasound is indicated because at least $20 \%$ of these men can have ipsilateral renal agenesis. For men with CFTR mutations, female partner testing and genetic counseling is critical prior to ART. In men with palpable vasa and suspected obstruction, a positive serum antisperm antibody indicates active spermatogenesis and eliminates unnecessary testicular biopsy before microsurgical reconstruction. ${ }^{9}$ EDO suspicion should prompt digital rectal examination to rule out midline cysts. Scrotal and transrectal ultrasound can detect structural abnormalities of the epididymis, seminal obstruction includes microsurgical reconstruction (vasovasostomy or vasoepididymostomy, respectively) when feasible using the multilayer microdot vasovasostomy technique (Fig. 2A and B) ${ }^{14,15}$ and longitudinal intussusception vasoepidiymostomy (LIVE) techniques ${ }^{16,17}$ as described previously (Fig. 2C). Both techniques, pioneered at Cornell, require adherence to standard microsurgical tenets including tension-free, water-tight, precise anastomosis with meticulous preservation of blood supply. For vasoepididymostomy or redo reconstruction surgery, sperm retrieval and cryopreservation for future IVF/ICSI should be performed intraoperatively as an alternative solution if reconstruction proves unsuccessful. ${ }^{18}$

Approximately 6\% of the 600000 men undergoing vasectomy annually ultimately desire vasectomy reversal. The decision for reconstruction is multifactorial, based upon number of offspring desired, past surgical history, prior fertility, female partner characteristics (age or infertility), as well as religious and financial background. Outcomes of microsurgical reconstruction have improved over the past four decades and currently include $70-99.5 \%$ patency $/ 36-92 \%$ pregnancy rates for $\mathrm{VV}$ and $30-90 \%$ patency $/ 20-50 \%$ pregnancy rates for VE. ${ }^{19-21}$ Predictors of microsurgical reconstruction outcomes include intraoperative vasal fluid quality and sperm granuloma presence, vasal obstructive interval, and microsurgeon experience. ${ }^{22}$ Cost-effectiveness analysis indicates that microsurgical reconstruction is the safest and most financially-sound management option for vasal and epididymal obstruction. ${ }^{19,23,24}$ Transurethral resection of the ejaculatory ducts (TURED), or alternatively with simultaneous microsurgical sperm retrieval, may be completed for ejaculatory duct obstruction. ${ }^{25}$ However, TURED may not be completed with concomitant VE for secondary epididymal obstruction since this is rarely successful.

For cases not amenable to surgical intervention such as men with CBAVD, microsurgical epididymal sperm aspiration (MESA) combined with IVF/ICSI is the treatment of choice. ${ }^{26,27}$ Retrieved sperm from men with OA may be cryopreserved as data indicate equivalent excellent outcomes with fresh or frozen sperm used for IVF/ICSI. ${ }^{28,29}$ Although MESA yields far more sperm typically than testicular sources, testicular and epididymal sperm from men with OA have been identified to yield similar outcomes with IVF/ICSI. ${ }^{30}$ 


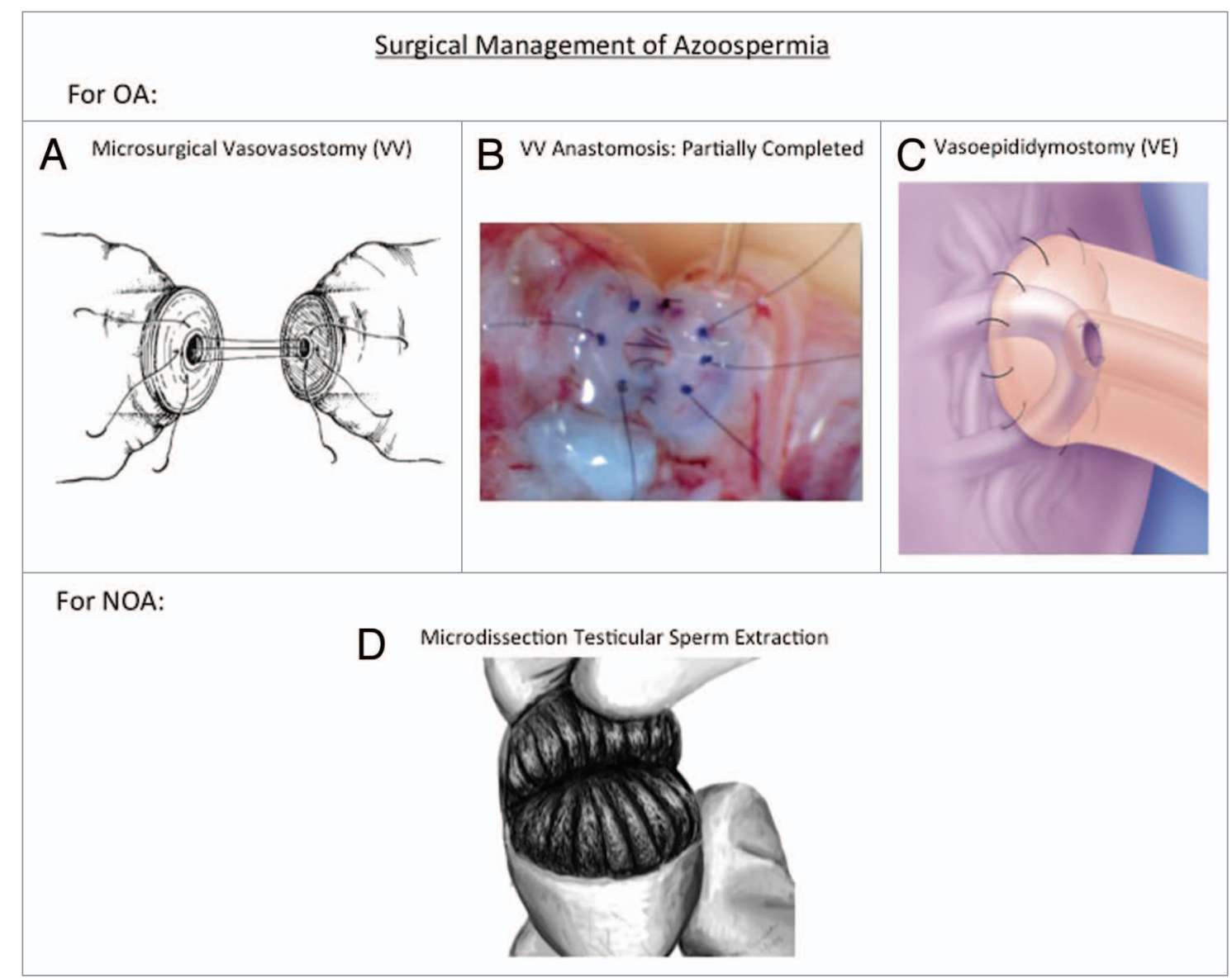

Figure 2. (A) Vasovasostomy (VV) with mucosal stitches placed prior to tying. (B) Vasovasostomy (VV) anastomosis partially completed: the posterior side has been completed and anterior 3 mucosal sutures have been placed according to the microdot technique and prepared for tying. (C) Completed VE anastomosis using longitudinal intussusception VE technique (LIVE). The vasal lumen reaches the desired epididymal tubule without tension after completed LIVE procedure. (D) Microdissection testicular sperm extraction (MicroTESE) with testis opened along equatorial plane at mid-portion revealing seminiferous tubules.

\section{Etiology of NOA}

NOA includes primary testicular failure (elevated LH, FSH, small testes affecting up to $10 \%$ of men presenting with infertility), secondary testicular failure (congenital hypgonadotropic hypogonadism with decreased LH and FSH, small testes), and those with an incomplete or ambiguous picture of testicular failure (either increased FSH and normal volume testes, normal FSH and small testes, or normal FSH and normal testis volume) (Fig. 1). For example, maturation arrest is often associated with normal FSH and/or testis volume and is associated with genetic abnormalities including MLH1 mutations, which are characterized by decreased recombination frequency. ${ }^{31}$ Serum testosterone, LH, FSH, and prolactin can distinguish between NOA and OA. Patients typically demonstrate small soft, atrophic testes unlike normal volume testes in OA. NOA may result from prior toxic exposures (i.e., chemotherapy, radiation) or history of abnormal development, cryptorchidism, or large varicoceles.

\section{Diagnosis of NOA}

Karyotype and Y chromosome microdeletion (YCMD) tests are warranted in men with NOA without history of prior fertility, obstruction of male reproductive tract, or toxic exposures. ${ }^{32}$ Karyotype analysis identifies both numeric and structural abnormalities of chromosomes, which are identified to be abnormal in up to $19 \%$ of men with NOA. The most frequently identified karyotype abnormality is Klinefelter syndrome (47,XXY; found in 1/600 men), while Robertsonian translocations (fusion of long arms of two acrocentric chromosomes 13, 14, 15, 21, or 22) are a frequent structural abnormality. Declining spermatogenesis is correlated with increasing number of $\mathrm{X}$ chromosomes. YCMD of three azoospermic factor (AZF) regions located in Yq11 (long arm of the Y chromosome) encode proteins influencing spermatogenesis mapped initially in 1976 with additional ensuing characterization. ${ }^{33,34} \mathrm{PCR}$ amplification using sequencetagged sites (STS) identifies abnormalities in the AZF regions $(\mathrm{AZFa}, \mathrm{AZFb}, \mathrm{AZFc})$ in $10-20 \%$ of azoospermic men, which 
Table 1. Microdissection TESE outcomes at Cornell

\begin{tabular}{|c|c|c|}
\hline Condition & Overall sperm retrieval rate & Pregnancy rate \\
\hline & per micro-TESE cycle & \\
\hline Cryptorchidism & $64 \%$ & $50 \%$ \\
\hline Post-chemotherapy azoospermia & $48 \%$ & $40 \%$ \\
\hline KS (classic and mosaic) & $65 \%$ & $40 \%$ \\
\hline AZFc deletion (Y chromosome microdeletion) & $72 \%$ & $46 \%$ \\
\hline Uniform Maturation Arrest & $50 \%$ & $29 \%$ \\
\hline Sertoli cell only & $44 \%$ & $46 \%$ \\
\hline
\end{tabular}

have prognostic implications. $\mathrm{AZFa}, \mathrm{AZFb}$, and $\mathrm{AZFb}+\mathrm{c}$ have not previously been associated with successful sperm retrieval, while AZFc microdeletions are associated with successful sperm retrieval in up to $80 \%$ of cases; however, male offspring will also manifest AZFc microdeletion and have the same fertility problem as their fathers. ${ }^{35,36}$

For men with congenital hypogonadotropic hypogonadism, the most common form is Kallmann syndrome, which manifests with a spectrum of symptoms, including anosmia/hyposmia due to faulty migration of GnRH-secreting neurons from the nasal olfactory epithelium to the basal hypothalamus during embryogenesis. ${ }^{37}$ Due to absent hypothalamic GnRH, the pituitary is not stimulated to produce LH and FSH, although pituitary gonadotrophs are present and normal. Therefore, both spermatogenesis and testosterone production by the testes are not stimulated. Specific genetic testing is warranted and varies depending on the inheritance pattern (X-linked or autosomal) for KAL1 (Xp22.32), FGFR1 (8p11.2-11.1), and other genes. ${ }^{38,39}$ KAL1 mutations are noted in $15-50 \%$ of familial X-linked and $10 \%$ of sporadic cases. Patients present with variable clinical picture including absent or incomplete pubertal development, severe hypogonadism, anosmia, and occasionally impaired hearing or oral anomalies. Therapy includes pulsatile GnRH administration, or more practically, hCG (to replace LH), recombinant FSH, hMG. ${ }^{40}$ Sperm production may be induced with up to $1-2$ y of treatment in the vast majority of patients with excellent pregnancy rates even with low sperm counts. NOA patients with ambiguous clinical picture and low semen volume should undergo CFTR mutation (otherwise typically reserved for OA patients with suspected CUAVD, CBAVD) testing since this could be related to seminal vesicle atresia. In applicable cases, preimplantation genetic diagnosis may be considered given potential risk of increased pregnancy loss and offspring abnormalities. ${ }^{41}$ Genetic counseling is requisite before and after any genetic testing.

\section{Management of NOA}

Prior to microsurgical testicular sperm retrieval techniques and IVF/ICSI, donor insemination was the only option available to men with NOA. Microdissection testicular sperm extraction (microTESE) in combination with IVF/ICSI, for appropriate azoospermic candidates based on laboratory and genetic testing (i.e., Klinefelter syndrome, AZFc microdeletion patients), yields sperm in approximately $60 \%$ of cases with increased sperm retrieval rates and decreased structural alteration of the testis, ${ }^{42,43}$ even with elevated FSH levels or decreased testicular volume, ${ }^{44}$ compared with non-microsurgical approach (Table 1; Fig. 2D). ${ }^{45,46}$ Additionally, in hypogonadal men with NOA, there is no relationship between preoperative testicular volume, FSH levels, or testosterone response to hormonal therapy and TESE sperm retrieval outcomes. ${ }^{47}$ Klinefelter patients, however, do demonstrate improved sperm retrieval outcomes when preoperative testosterone increased to greater than $250 \mathrm{ng} / \mathrm{dl}$ with medical therapy $(77 \%$ with testosterone response vs $55 \%$ without response). ${ }^{48}$ The benefits of microTESE have also been demonstrated for men with history of chemotherapy-related NOA (mean SRR of 43\%) with best results for patients with testicular cancer and worst results for patients with sarcoma history. ${ }^{49}$ Aside from men with hypogonadotropic hypogonadism or oligospermia, there is minimal evidence of any benefit to providing supplemental gonadotropins for men with NOA due to primary testicular failure. ${ }^{50,51}$ Additional genetic understanding of $\mathrm{LH}$ and FSH receptors and aromatase could select men who may derive benefit.

Approximately $15-20 \%$ of men with varicoceles experience fertility issues. ${ }^{52,53}$ For men with NOA and varicocele, microsurgical varicoceletomy has been reported to improve spermatogenesis (and decrease scrotal temperature ${ }^{54}$ and DNA fragmentation ${ }^{55}$ ) in the testis leading to return of sperm to the ejaculate in $22-55 \%$ of men, with $10-40 \%$ of men avoiding TESE. ${ }^{56-58}$ Recovery of sperm to the ejaculate may be dependent on testicular histology, with hypospermatogenesis and late maturation arrest demonstrating this favorable outcome, while early maturation arrest and Sertoli cell-only histology consistently require TESE. ${ }^{59}$ Some studies demonstrate that the chance for successful sperm retrieval in men with NOA undergoing varicocelectomy is equivalent to those without varicocele repair, while other studies show improvement in sperm retrieval rates (Table 2). ${ }^{56,60}$ Cost-effectiveness analysis indicates that varicocelctomy may be cost-effective for only some patients when compared with upfront testicular sperm extraction with ICSI for men with NOA. Overall, decision for varicocelectomy in men with NOA must take into account the age of the female partner, grade of varicocele, along with the best available data from clinical trials. ${ }^{61}$

Additional genetic testing in the future, including analysis of sperm small non-coding RNA (sncRNA), mRNA, microRNA (miRNA), piwi-interacting RNA 
Table 2. Varicocelectomy outcomes for men with non-obstructive azoospermia

\begin{tabular}{|c|c|c|c|c|}
\hline Study & $\begin{array}{c}\text { Number of } \\
\text { patients }\end{array}$ & $\begin{array}{c}\text { Mean post-operative sperm } \\
\text { concentration }(\mathbf{x 1 0} / \mathrm{ml})\end{array}$ & Return of sperm to ejaculate & Pregnancy rate \\
\hline Matthews, 1998 [57] & 22 & 2.2 & $12 / 22(55 \%)$ & $3 / 22(15 \%)$ \\
\hline Kim, 1999 [66] & 28 & 1.2 & $12 / 28(43 \%)$ & $2 / 28(7 \%)$ \\
\hline Kadioglu, 2001 [67] & 24 & 0.04 & $5 / 24(21 \%)$ & $0 / 24(0 \%)$ \\
\hline Schlegel, 2004 [56] & 31 & N/A & $7 / 31(22 \%)$ & $0 / 31(0 \%)$ \\
\hline Cakan, 2004 [68] & 13 & 0.7 & $3 / 13(23 \%)$ & $0 / 13(0 \%)$ \\
\hline Esteves 2005 [69] & 17 & 0.8 & $8 / 17(47 \%)$ & $1 / 17(6 \%)$ \\
\hline Gat, 2005 [70] & 32 & 3.8 & $18 / 32(56 \%)$ & $4 / 18(12 \%)$ \\
\hline Poulakis, 2006 [71] & 14 & 3.1 & $7 / 14(50 \%)$ & $2 / 14(14 \%)$ \\
\hline $\begin{array}{c}\text { Pasqualotto, 2006 } \\
\text { [72] }\end{array}$ & 27 & 0.87 & $9 / 27(33 \%)$ & $1 / 33(3 \%)$ \\
\hline Lee, 2007[58] & 19 & 0.36 & $7 / 19(36 \%)$ & $1 / 19(5 \%)$ \\
\hline Ishikawa, 2008 [73] & 6 & 0.2 & $2 / 6(33 \%)$ & $0 / 6(0 \%)$ \\
\hline Cocuzza, 2009 [74] & 10 & 5.5 & $3 / 10(30 \%)$ & N/A \\
\hline Youssef, 2009 [75] & 51 & 3.56 & $14 / 51(28 \%)$ & $2 / 51(4 \%)$ \\
\hline Abdel-Meguid, 2012 & $3159]$ & 2.3 & $117 / 325(36 \%)$ & N/A (32\%) \\
\hline Overall & 325 & 1.89 & $16 / 276(6 \%)$ \\
\hline
\end{tabular}

Adapted from: Schlegel and Goldstein, 2011. ${ }^{76}$

(piRNA), epigenetic modifications (histones/protamines), posttranslational protein-modified gene products, ${ }^{62}$ DNA damage repair gene SNPs, ${ }^{63}$ and copy number variation affecting spermatogenic failure may further refine diagnosis and treatment of azoospermia. ${ }^{64,65}$

\section{Conclusion}

Differentiation of OA from NOA is required to formulate diagnostic and management options for azoospermic patients. OA occurs secondary to obstruction of the male reproductive tract, and is diagnosed through a combination of history/physical examination, laboratory testing, genetics (CFTR for congenital OA), and imaging studies as needed. If vasal or epididymal obstruction are present, microsurgical reconstruction, if feasible based on multifactorial decision analysis, provides efficacious, safe, and costeffective outcomes using the most recent available techniques. If obstructive etiology or the patient is not amenable to microsurgical reconstruction, microsurgical sperm aspiration provides excellent outcomes in conjunction with ART since normal spermatogenesis is usually present in OA. Patients with NOA (which includes primary testicular failure and secondary testicular failure) is differentiated from OA by clinical assessment (testis consistency/volume), laboratory testing (FSH), and genetic testing (karyotype, YCMD, or specific genetic testing for $\mathrm{HH}$ ). Management includes microdissection testicular sperm extraction and IVF/ICSI. In the case of varicocele with NOA, varicocelectomy may prove beneficial. Future study of biologic and genetic mechanisms will optimize diagnosis and prognosis for azoospermic patients.

Author: Please include in-text citation for references 66-75.

\section{Disclosure of Potential Conflicts of Interest}

No potential conflicts of interest were disclosed.

\section{References}

1. Practice Committee of American Society for Reproductive Medicine in collaboration with Society for Male Reproduction and Urology. The management of infertility due to obstructive azoospermia. Fertil Steril 2008; 90(Suppl):S121-4; PMID:19007607; http://dx.doi.org/10.1016/j. fertnstert.2008.08.096

2. Jow WW, Steckel J, Schlegel PN, Magid MS, Goldstein M. Motile sperm in human testis biopsy specimens. J Androl 1993; 14:194-8; PMID:8407575

3. Jarow JP, Espeland MA, Lipshultz LI. Evaluation of the azoospermic patient. J Urol 1989; 142:62-5; PMID:2499695
4. Fuchs EF, Burt RA. Vasectomy reversal performed 15 years or more after vasectomy: correlation of pregnancy outcome with partner age and with pregnancy results of in vitro fertilization with intracytoplasmic sperm injection. Fertil Steril 2002; 77:516-9; PMID:11872205; $\quad$ http://dx.doi.org/10.1016/ S0015-0282(01)03219-8

5. Boorjian S, Lipkin M, Goldstein M. The impact of obstructive interval and sperm granuloma on outcome of vasectomy reversal. J Urol 2004; 171:3046; PMID:14665900; http://dx.doi.org/10.1097/01. ju.0000098652.35575.85

6. Hsiao W, Sultan R, Lee R, Goldstein M. Increased follicle-stimulating hormone is associated with higher assisted reproduction use after vasectomy reversal. J Urol 2011; 185:2266-71; PMID:21497850; http:// dx.doi.org/10.1016/j.juro.2011.02.011
7. American College of Obstetricians and Gynecologists Committee on Genetics. ACOG Committee Opinion No. 486: Update on carrier screening for cystic fibrosis. Obstet Gynecol 2011; 117:102831; PMID:21422883; http://dx.doi.org/10.1097/ AOG.0b013e31821922c2

8. Pratt VM, Caggana M, Bridges C, Buller AM, DiAntonio L, Highsmith WE, Holtegaard LM, Muralidharan K, Rohlfs EM, Tarleton J, et al. Development of genomic reference materials for cystic fibrosis genetic testing. J Mol Diagn 2009; 11:18693; PMID:19359498; http://dx.doi.org/10.2353/ jmoldx.2009.080149 
9. Lee R, Goldstein M, Ullery BW, Ehrlich J, Soares M, Razzano RA, Herman MP, Callahan MA, Li PS, Schlegel PN, et al. Value of serum antisperm antibodies in diagnosing obstructive azoospermia. J Urol 2009; 181:264-9; PMID:19013620; http://dx.doi. org/10.1016/j.juro.2008.09.004

10. Abdulwahed SR, Mohamed EE, Taha EA, Saleh MA, Abdelsalam YM, ElGanainy EO. Sensitivity and specificity of ultrasonography in predicting etiology of azoospermia. Urology 2013; 81:96771; PMID:23453653; http://dx.doi.org/10.1016/j. urology.2013.01.001

11. Rastrelli G, Corona G, Lotti F, Boddi V, Mannucci E, Maggi M. Relationship of Testis Size and LH Levels with Incidence of Major Adverse Cardiovascular Events in Older Men with Sexual Dysfunction. J Sex Med 2013; 10:2761-73; PMID:23844651; http:// dx.doi.org/10.1111/jsm. 12270

12. Hotaling JM, Walsh TJ. Male infertility: a risk factor for testicular cancer. Nat Rev Urol 2009; 6:5506; PMID:19724246; http://dx.doi.org/10.1038/ nrurol.2009.179

13. Petersen SM, Dandanell M, Rasmussen LJ, Gerdes AM, Krogh LN, Bernstein I, Okkels H, Wikman F, Nielsen FC, Hansen TV. Functional examination of MLH1, MSH2, and MSH6 intronic mutations identified in Danish colorectal cancer patients. BMC Med Genet 2013; 14:103; PMID:24090359; http:// dx.doi.org/10.1186/1471-2350-14-103

14. Goldstein M. Microspike approximator for vasovasostomy. J Urol 1985; 134:74; PMID:4009827

15. Goldstein M, Li PS, Matthews GJ. Microsurgical vasovasostomy: the microdot technique of precision suture placement. J Urol 1998; 159:188-90; PMID:9400469; $\quad$ http://dx.doi.org/10.1016/ S0022-5347(01)64053-9

16. Chan PT, Brandell RA, Goldstein M. Prospective analysis of outcomes after microsurgical intussusception vasoepididymostomy. BJU Int 2005; 96:598-601; PMID:16104917; http://dx.doi. org/10.1111/j.1464-410X.2005.05691.x

17. Chan PT, Li PS, Goldstein M. Microsurgical vasoepididymostomy: a prospective randomized study of 3 intussusception techniques in rats. J Urol 2003; 169:1924-9; PMID:12686875; http://dx.doi. org/10.1097/01.ju.0000059360.97108.c4

18. Schrepferman CG, Carson MR, Sparks AE, Sandlow JI. Need for sperm retrieval and cryopreservation at vasectomy reversal. J Urol 2001; 166:17879; PMID:11586225; http://dx.doi.org/10.1016/ S0022-5347(05)65676-5

19. Kolettis PN, Thomas AJ Jr. Vasoepididymostomy for vasectomy reversal: a critical assessment in the era of intracytoplasmic sperm injection. J Urol 1997; 158:467-70; PMID:9224325; http://dx.doi. org/10.1016/S0022-5347(01)64504-X

20. Silber SJ, Grotjan HE. Microscopic vasectomy reversal 30 years later: a summary of 4010 cases by the same surgeon. J Androl 2004; 25:845-59; PMID:15477352

21. Matthews GJ, Schlegel PN, Goldstein M. Patency following microsurgical vasoepididymostomy and vasovasostomy: temporal considerations. J Urol 1995; 154:2070-3; PMID:7500460; http://dx.doi. org/10.1016/S0022-5347(01)66697-7

22. Hsiao W, Goldstein M, Rosoff JS, Piccorelli A, Kattan MW, Greenwood EA, Mulhall JP. Nomograms to predict patency after microsurgical vasectomy reversal. J Urol 2012; 187:607-12; PMID:22177169; http://dx.doi.org/10.1016/j.juro.2011.10.044

23. Pavlovich CP, Schlegel PN. Fertility options after vasectomy: a cost-effectiveness analysis. Fertil Steril 1997; 67:133-41; PMID:8986698; http://dx.doi. org/10.1016/S0015-0282(97)81870-5

24. Hsieh MH, Meng MV, Turek PJ. Markov modeling of vasectomy reversal and ART for infertility: how do obstructive interval and female partner age influence cost effectiveness? Fertil Steril 2007; 88:8406; PMID:17544418; http://dx.doi.org/10.1016/j. fertnstert.2006.11.199
25. Meacham RB, Hellerstein DK, Lipshultz LI. Evaluation and treatment of ejaculatory duct obstruction in the infertile male. Fertil Steril 1993; 59:393-7; PMID:8425637

26. Schlegel PN, Cohen J, Goldstein M, Alikani M, Adler A, Gilbert BR, Palermo GD, Rosenwaks Z. Cystic fibrosis gene mutations do not affect sperm function during in vitro fertilization with micromanipulation for men with bilateral congenital absence of vas deferens. Fertil Steril 1995; 64:421-6; PMID:7542209

27. Anger JT, Wang GJ, Boorjian SA, Goldstein M. Sperm cryopreservation and in vitro fertilization/ intracytoplasmic sperm injection in men with congenital bilateral absence of the vas deferens: a success story. Fertil Steril 2004; 82:1452-4; PMID:15533379; http://dx.doi.org/10.1016/j.fertnstert.2004.05.079

28. Esteves SC, Lee W, Benjamin DJ, Seol B, Verza S Jr., Agarwal A. Reproductive potential of men with obstructive azoospermia undergoing percutaneous sperm retrieval and intracytoplasmic sperm injection according to the cause of obstruction. J Urol 2013; 189:232-7; PMID:23174251; http://dx.doi. org/10.1016/j.juro.2012.08.084

29. Janzen N, Goldstein M, Schlegel PN, Palermo GD, Rosenwaks Z, Hariprashad J. Use of electively cryopreserved microsurgically aspirated epididymal sperm with IVF and intracytoplasmic sperm injection for obstructive azoospermia. Fertil Steril 2000; 74:696701; PMID:11020509; http://dx.doi.org/10.1016/ S0015-0282(00)01496-5

30. Van Peperstraten A, Proctor ML, Johnson NP, Philipson G. Techniques for surgical retrieval of sperm prior to intra-cytoplasmic sperm injection (ICSI) for azoospermia. Cochrane Database Syst Rev 2008; CD002807; PMID:18425884

31. Gonsalves J, Sun F, Schlegel PN, Turek PJ, Hopps CV, Greene C, Martin RH, Pera RA. Defective recombination in infertile men. Hum Mol Genet 2004; 13:2875-83; PMID:15385442; http://dx.doi. org/10.1093/hmg/ddh302

32. Male Infertility Best Practice Policy Committee of the American Urological Association; Practice Committee of the American Society for Reproductive Medicine. Report on evaluation of the azoospermic male. Fertil Steril 2006; 86(Suppl 1):S210-5; PMID:17055824; $\quad$ http://dx.doi.org/10.1016/j. fertnstert.2006.08.030

33. Tiepolo L, Zuffardi O. Localization of factors controlling spermatogenesis in the nonfluorescent portion of the human Y chromosome long arm. Hum Genet 1976; 34:119-24; PMID:1002136; http:// dx.doi.org/10.1007/BF00278879

34. Vogt PH, Edelmann A, Kirsch S, Henegariu O, Hirschmann P, Kiesewetter F, Köhn FM, Schill WB, Farah S, Ramos C, et al. Human Y chromosome azoospermia factors (AZF) mapped to different subregions in Yq11. Hum Mol Genet 1996; 5:933 43; PMID:8817327; http://dx.doi.org/10.1093/ $\mathrm{hmg} / 5.7 .933$

35. Hopps CV, Mielnik A, Goldstein M, Palermo GD, Rosenwaks Z, Schlegel PN. Detection of sperm in men with $\mathrm{Y}$ chromosome microdeletions of the $\mathrm{AZFa}, \mathrm{AZFb}$ and $\mathrm{AZFc}$ regions. Hum Reprod 2003; 18:1660-5; PMID:12871878; http://dx.doi. org/10.1093/humrep/deg348

36. Choi JM, Chung P, Veeck L, Mielnik A, Palermo GD, Schlegel PN. AZF microdeletions of the Y chromosome and in vitro fertilization outcome. Fertil Steril 2004; 81:337-41; PMID:14967370; http://dx.doi. org/10.1016/j.fertnstert.2003.06.030

37. Schwanzel-Fukuda M, Bick D, Pfaff DW. Luteinizing hormone-releasing hormone (LHRH)-expressing cells do not migrate normally in an inherited hypogonadal (Kallmann) syndrome. Brain Res Mol Brain Res 1989; 6:311-26; PMID:2687610; http://dx.doi. org/10.1016/0169-328X(89)90076-4
38. Legouis R, Hardelin JP, Levilliers J, Claverie JM, Compain S, Wunderle V, Millasseau P, Le Paslier $\mathrm{D}$, Cohen D, Caterina D, et al. The candidate gene for the X-linked Kallmann syndrome encodes a protein related to adhesion molecules. Cell 1991; 67:423-35; PMID:1913827; http://dx.doi. org/10.1016/0092-8674(91)90193-3

39. Silveira LF, Trarbach EB, Latronico AC. Genetics basis for GnRH-dependent pubertal disorders in humans. Mol Cell Endocrinol 2010; 324:30-8; PMID:20188792; $\quad$ http://dx.doi.org/10.1016/j. mce.2010.02.023

40. Warne DW, Decosterd G, Okada H, Yano Y, Koide $\mathrm{N}$, Howles CM. A combined analysis of data to identify predictive factors for spermatogenesis in men with hypogonadotropic hypogonadism treated with recombinant human follicle-stimulating hormone and human chorionic gonadotropin. Fertil Steril 2009; 92:594-604; PMID:18930225; http://dx.doi. org/10.1016/j.fertnstert.2008.07.1720

41. Escudero T, Abdelhadi I, Sandalinas M, Munné S. Predictive value of sperm fluorescence in situ hybridization analysis on the outcome of preimplantation genetic diagnosis for translocations. Fertil Steril 2003; 79(Suppl 3):1528-34; PMID:12801555; http://dx.doi.org/10.1016/S0015-0282(03)00252-8

42. Ramasamy R, Yagan N, Schlegel PN. Structural and functional changes to the testis after conventional versus microdissection testicular sperm extraction. Urology 2005; 65:1190-4; PMID:15922422; http:// dx.doi.org/10.1016/j.urology.2004.12.059

43. Schiff JD, Palermo GD, Veeck LL, Goldstein M Rosenwaks Z, Schlegel PN. Success of testicula sperm extraction [corrected] and intracytoplasmic sperm injection in men with Klinefelter syndrome. J Clin Endocrinol Metab 2005; 90:6263-7; PMID:16131585; http://dx.doi.org/10.1210/ jc. 2004-2322

44. Ramasamy R, Lin K, Gosden LV, Rosenwaks Z, Palermo GD, Schlegel PN. High serum FSH levels in men with nonobstructive azoospermia does not affect success of microdissection testicular sperm extraction. Fertil Steril 2009; 92:590-3; PMID:18973887; http://dx.doi.org/10.1016/j.fertnstert.2008.07.1703

45. Su LM, Palermo GD, Goldstein M, Veeck LL, Rosenwaks Z, Schlegel PN. Testicular sperm extraction with intracytoplasmic sperm injection for nonobstructive azoospermia: testicular histology can predict success of sperm retrieval. J Uro 1999; 161:112-6; PMID:10037381; http://dx.doi. org/10.1016/S0022-5347(01)62079-2

46. Schlegel PN. Testicular sperm extraction: microdissection improves sperm yield with minimal tissue excision. Hum Reprod 1999; 14:131-5; PMID:10374109; http://dx.doi.org/10.1093/humrep/14.1.131

47. Reifsnyder JE, Ramasamy R, Husseini J, Schlege PN. Role of optimizing testosterone before microdissection testicular sperm extraction in men with nonobstructive azoospermia. J Urol 2012; 188:532 6; PMID:22704105; http://dx.doi.org/10.1016/j. juro.2012.04.002

48. Ramasamy R, Ricci JA, Leung RA, Schlegel PN Successful repeat microdissection testicular sperm extraction in men with nonobstructive azoospermia. J Urol 2011; 185:1027-31; PMID:21247600; http:// dx.doi.org/10.1016/j.juro.2010.10.066

49. Hsiao W, Stahl PJ, Osterberg EC, Nejat E, Palermo GD, Rosenwaks Z, Schlegel PN. Successful treatment of postchemotherapy azoospermia with microsurgical testicular sperm extraction: the Weill Cornell experience. J Clin Oncol 2011; 29:160711; PMID:21402606; http://dx.doi.org/10.1200/ JCO.2010.33.7808

50. Hussein A, Ozgok Y, Ross L, Niederberger C. Clomiphene administration for cases of nonobstructive azoospermia: a multicenter study. J Androl 2005; 26:787-91, discussion 792-3; PMID:16291975; http://dx.doi.org/10.2164/jandrol.04180 
51. Pavlovich CP, King P, Goldstein M, Schlegel PN. Evidence of a treatable endocrinopathy in infertile men. J Urol 2001; 165:837-41; PMID:11176482; http://dx.doi.org/10.1016/S0022-5347(05)66540-8

52. Goldstein M. Surgical Management of Male Infertility, in Campbell-Walsh Urology, A.J. Wein, et al., Editors. 2012, Elsevier Saunders: Philadelphia, PA. p. 648-687.

53. Gorelick JI, Goldstein M. Loss of fertility in men with varicocele. Fertil Steril 1993; 59:613-6; PMID:8458466

54. Wright EJ, Young GP, Goldstein M. Reduction in testicular temperature after varicocelectomy in infertile men. Urology 1997; 50:257-9; PMID:9255298; http://dx.doi.org/10.1016/S0090-4295(97)00191-X

55. Zini A, Azhar R, Baazeem A, Gabriel MS. Effect of microsurgical varicocelectomy on human sperm chromatin and DNA integrity: a prospective trial. Int J Androl 2011; 34:14-9; PMID:20132347; http:// dx.doi.org/10.1111/j.1365-2605.2009.01048.x

56. Schlegel PN, Kaufmann J. Role of varicocelectomy in men with nonobstructive azoospermia. Fertil Steri 2004; 81:1585-8; PMID:15193481; http://dx.doi. org/10.1016/j.fertnstert.2003.10.036

57. Matthews GJ, Matthews ED, Goldstein M. Induction of spermatogenesis and achievement of pregnancy after microsurgical varicocelectomy in men with azoospermia and severe oligoasthenospermia. Fertil Steril 1998; 70:71-5; PMID:9660424; http://dx.doi. org/10.1016/S0015-0282(98)00108-3

58. Lee JS, Park HJ, Seo JT. What is the indication of varicocelectomy in men with nonobstructive azoospermia? Urology 2007; 69:352-5; PMID:17320677; http://dx.doi.org/10.1016/j.urology.2006.10.010

59. Abdel-Meguid TA. Predictors of sperm recovery and azoospermia relapse in men with nonobstructive azoospermia after varicocele repair. J Uro 2012; 187:222-6; PMID:22100001; http://dx.doi. org/10.1016/j.juro.2011.09.047

60. Inci K, Hascicek M, Kara O, Dikmen AV, Gürgan T, Ergen A. Sperm retrieval and intracytoplasmic sperm injection in men with nonobstructive azoospermia, and treated and untreated varicocele. J Urol 2009; 182:1500-5; PMID:19683732; http://dx.doi. org/10.1016/j.juro.2009.06.028
61. Lee R, Li PS, Goldstein M, Schattman G, Schlegel $\mathrm{PN}$. A decision analysis of treatments for nonobstructive azoospermia associated with varicocele. Fertil Steril 2009; 92:188-96; PMID:18706552; http:// dx.doi.org/10.1016/j.fertnstert.2008.05.053

62. Aston KI, Punj V, Liu L, Carrell DT. Genome-wide sperm deoxyribonucleic acid methylation is altered in some men with abnormal chromatin packaging or poor in vitro fertilization embryogenesis. Fertil Steril 2012; 97:285-92; PMID:22154369; http://dx.doi. org/10.1016/j.fertnstert.2011.11.008

63. Ji G, Long Y, Zhou Y, Huang C, Gu A, Wang X. Common variants in mismatch repair genes associated with increased risk of sperm DNA damage and male infertility. BMC Med 2012; 10:49; PMID:22594646; http://dx.doi.org/10.1186/1741-7015-10-49

64. Shen Y, Yan Y, Liu Y, Zhang S, Yang D, Zhang P, Li L, Wang Y, Ma Y, Tao D, et al. A significant effect of the TSPY1 copy number on spermatogenesis efficiency and the phenotypic expression of the gr/gr deletion. Hum Mol Genet 2013; 22:1679-95 PMID:23307928; http://dx.doi.org/10.1093/hmg/ ddt004

65. Krawetz SA, Kruger A, Lalancette C, Tagett R, Anton E, Draghici S, Diamond MP. A survey of small RNAs in human sperm. Hum Reprod 2011; 26:3401 12; PMID:21989093; http://dx.doi.org/10.1093/ humrep/der329

66. Kim ED, Leibman BB, Grinblat DM, Lipshultz LI. Varicocele repair improves semen parameters in azoospermic men with spermatogenic failure. J Uro 1999; 162:737-40; PMID:10458356; http://dx.doi org/10.1097/00005392-199909010-00031

67. Kadioglu A, Tefekli A, Cayan S, Kandirali E, Erdemir F, Tellaloglu S. Microsurgical inguinal varicocele repair in azoospermic men. Urology 2001; 57:328 33; PMID:11182347; http://dx.doi.org/10.1016/ S0090-4295(00) 00908-0

68. Cakan M, Altuğ U. Induction of spermatogenesis by inguinal varicocele repair in azoospermic men. Arch Androl 2004; 50:145-50; PMID:15204679; http:// dx.doi.org/10.1080/01485010490425250
69. Esteves SC, Glina S. Recovery of spermatogenesis after microsurgical subinguinal varicocele repair in azoospermic men based on testicular histology. Int Braz J Urol 2005; 31:541-8; PMID:16386122; http:// dx.doi.org/10.1590/S1677-55382005000600005

70. Gat Y, Bachar GN, Everaert K, Levinger U, Gornish $\mathrm{M}$. Induction of spermatogenesis in azoospermic men after internal spermatic vein embolization for the treatment of varicocele. Hum Reprod 2005; $20: 1013$ 7; PMID:15618245; http://dx.doi.org/10.1093/ humrep/deh706

71. Poulakis V, Ferakis N, de Vries R, Witzsch U, Becht E. Induction of spermatogenesis in men with azoospermia or severe oligoteratoasthenospermia after antegrade internal spermatic vein sclerotherapy for the treatment of varicocele. Asian J Androl 2006; 8:613-9; PMID:16847530; http://dx.doi. org/10.1111/j.1745-7262.2006.00157.x

72. Pasqualotto FF, Sobreiro BP, Hallak J, Pasqualotto $\mathrm{EB}$, Lucon AM. Induction of spermatogenesis in azoospermic men after varicocelectomy repair: an update. Fertil Steril 2006; 85:635-9; PMID:16500331; http://dx.doi.org/10.1016/j.fertnstert.2005.08.043

73. Ishikawa T, Kondo Y, Yamaguchi K, Sakamoto Y, Fujisawa M. Effect of varicocelectomy on patients with unobstructive azoospermia and severe oligospermia. BJU Int 2008; 101:216-8; PMID:17941933

74. Cocuzza M, Pagani R, Lopes RI, Athayde KS, Lucon AM, Srougi M, Hallak J. Use of subinguinal incision for microsurgical testicular biopsy during varicocelectomy in men with nonobstructive azoospermia. Fertil Steril 2009; 91:925-8; PMID:18644594; http:// dx.doi.org/10.1016/j.fertnstert.2007.12.065

75. Youssef T, Abd-Elaal E, Gaballah G, Elhanbly S, Eldosoky E. Varicocelectomy in men with nonobstructive azoospermia: is it beneficial? Int J Surg 2009; 7:356-60; PMID:19482096; http://dx.doi. org/10.1016/j.ijsu.2009.05.009

76. Schlegel PN, Goldstein M. Alternate indications for varicocele repair: non-obstructive azoospermia, pain, androgen deficiency and progressive testicular dysfunction. Fertil Steril 2011; 96:1288 93; PMID:22130099; http://dx.doi.org/10.1016/j. fertnstert.2011.10.033 